Chapman University

Chapman University Digital Commons

Education Faculty Articles and Research

Attallah College of Educational Studies

6-18-2019

\title{
School-Wide Implementation of Positive Behavioral Interventions and Supports in an Alternative School Setting: A Case Study
}

Amy-Jane Griffiths

Chapman University, agriffit@chapman.edu

Elena Lilles Diamond

Lewis and Clark College

James Alsip

Chapman University

Michael Furlong

University of California, Santa Barbara

Gale M. Morrison

University of California, Santa Barbara

See next page for additional authors

Follow this and additional works at: https://digitalcommons.chapman.edu/education_articles

Part of the Educational Assessment, Evaluation, and Research Commons, Educational

Leadership Commons, Educational Methods Commons, Educational Psychology Commons, Other

Education Commons, and the Social and Philosophical Foundations of Education Commons

\section{Recommended Citation}

Griffiths, A.J., Diamond, E.M., Alsip, J., Furlong, M., Morrison, G., \& Do, B. (2019). School-wide implementation of positive behavioral interventions and supports in an alternative school setting: A case study. Journal of Community Psychology. https://doi.org/ $10.1002 /$ jcop. 22203 


\section{School-Wide Implementation of Positive Behavioral Interventions and Supports in an Alternative School Setting: A Case Study}

\section{Comments}

This is the accepted version of the following article:

Griffiths, A.J., Diamond, E.M., Alsip, J., Furlong, M., Morrison, G., \& Do, B. (2019). School-wide implementation of positive behavioral interventions and supports in an alternative school setting: A case study. Journal of Community Psychology.

which has been published in final form at DOI: 10.1002 /jcop.22203. This article may be used for noncommercial purposes in accordance with Wiley Terms and Conditions for Self-Archiving.

\section{Copyright}

Wiley

\section{Authors}

Amy-Jane Griffiths, Elena Lilles Diamond, James Alsip, Michael Furlong, Gale M. Morrison, and Bich Do 
Running head: POSITIVE BEHAVIORAL SUPPORTS IN ALTERNATIVE EDUCATION

School-Wide Implementation of Positive Behavioral Interventions and Supports in an Alternative School Setting: A Case Study

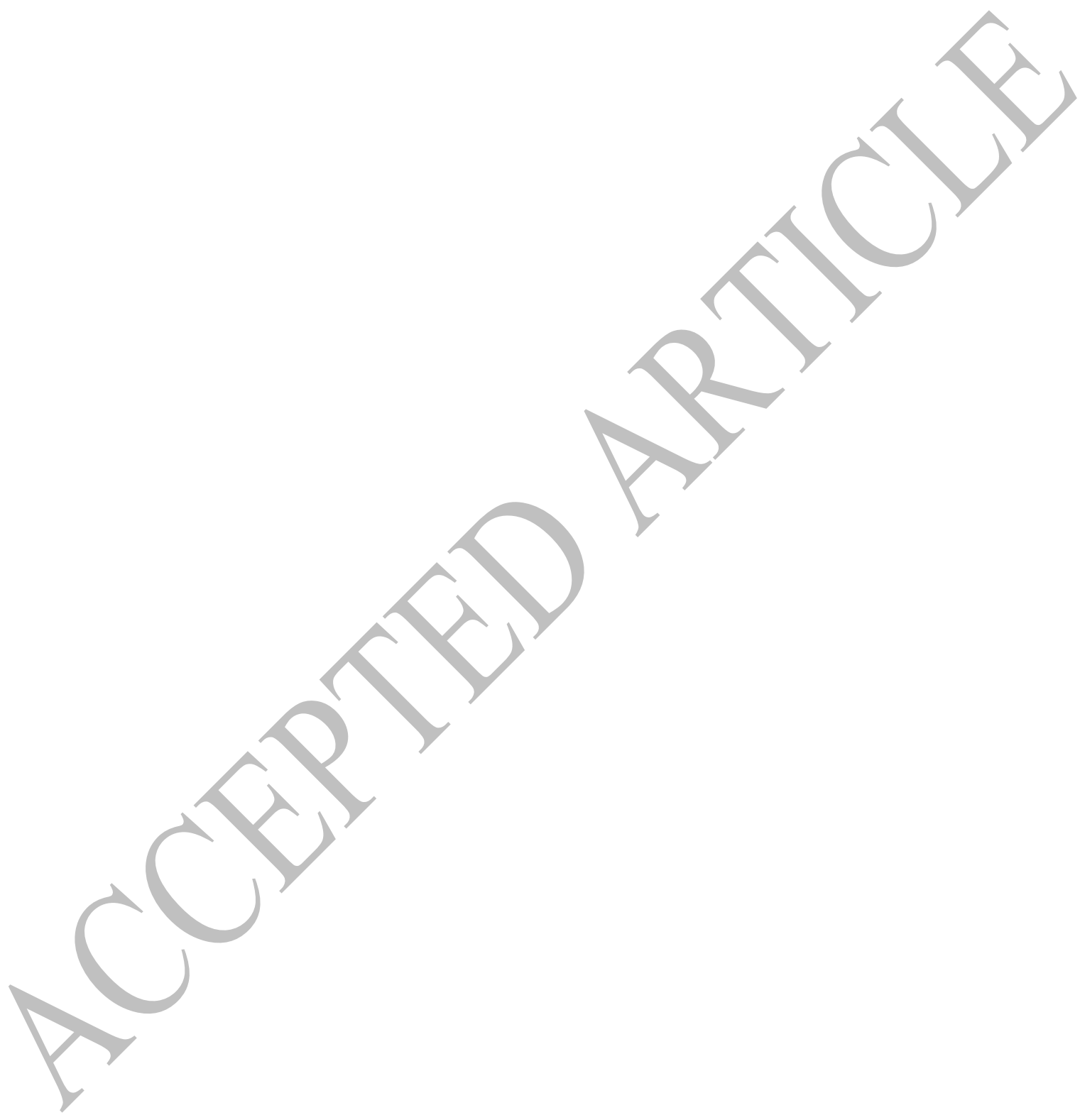




\begin{abstract}
Aims: The purpose of this one-year case study was to identify how School-Wide Positive Behavioral Interventions and Supports (SW-PBIS) can be adapted to meet the needs of students in alternative schools and to evaluate the early impact of SW-PBIS on discipline outcomes. Methods: Suggestions for adaptations are provided at each stage of the intervention process with a focus on buy-in, training, data collection, and resource allocation.

Results: Data from this case study included information about key components of the implementation process as well as initial outcomes. Process data revealed the importance of stakeholder buy-in, training opportunities, and potential adaptations to the framework. Outcome data from the first year of implementation indicated that the number of incident reports did not significantly differ from the baseline; however, there was a reduction in defiance-related behaviors and in increase in on-task behaviors.

Conclusion: This study contributes to the determination of the efficacy of SW-PBIS in a historically more punitive environment. Given the initial positive response and lessons learned, it is believed that, with the support of additional Tier 2 and Tier 3 interventions, SW-PBIS may be an appropriate framework to support students in alternative schools.
\end{abstract}

Keywords: school-wide intervention, adolescent, positive behavior support, alternative school 
Student misbehavior, including internalizing (e.g., anxiety, withdrawal) and externalizing (e.g., aggression, hyperactivity) problems, is one of the most frequently cited concerns in public schools today (Abry et al., 2017). Behavioral problems often lead to negative student-teacher relationships and less time spent on academic instruction (Kauffman \& Brigham, 2009) and potentially affect student mental health, well-being, and academic skill development (Cohen, 2006; Cook, Williams, Guerra, Kim, \& Sadek, 2010). Due to the negative impacts of misbehavior on school climate and student learning, there has been a shift toward universal prevention and intervention as a means to address the needs of not only students who misbehave, but all students (Eagle, Dowd-Eagle, Snyder, \& Gibbons Holtzman, 2015). Among these universal prevention strategies, School-Wide Positive Behavioral Interventions and Supports (SW-PBIS) has become an increasingly popular evidence-based framework designed to decrease negative behaviors while increasing positive interactions in schools (Ogulmus \& Vuran, 2016; Sugai \& Horner, 2009). The present case study has (a) an applied intervention emphasis; (b) offers insight into implementation of SW-PBIS in an alternative education setting, a topic that has received limited research attention; and (c) focuses on an empirical evaluation of an intervention systematically designed for students with emotional and behavioral disorders. Given the unique setting and population employed in the present study, we anticipate that this research could inform processes relevant to the design and implementation of sustainable interventions in community school settings.

\section{School-Wide Positive Behavioral Interventions and Support (SW-PBIS)}

Adopted by over 20,000 schools across all 50 states, SW-PBIS is a function-based prevention and intervention approach that seeks to replace challenging, disruptive, and 
aggressive behaviors with prosocial skills (Ogulmus \& Vuran, 2016; Positive Behavioral Interventions \& Supports, n.d.). Because students are most likely to reach their full academic and social-emotional potential in a safe and welcoming school climate, SW-PBIS targets the entire school population as a school-wide prevention and intervention framework. Aspects of an SW-PBIS include (a) defining positive behavioral expectations (Burke, Davis, Hagan-Burke, Lee, \& Fogarty, 2014); (b) directly teaching the identified expectations to all students (Sugai \& Horner, 2009); (c) maintaining a system that acknowledges and rewards students who meet expectations; (d) establishing a continuum of logical consequences (Sugai \& Horner, 2009); and (e) gathering and using data for decision-making purposes (Kincaid et al., 2016). SW-PBIS is grounded in the idea that reinforcement of positive behaviors leads to greater positive behavioral change than punishing misbehaviors.

Research supports the effectiveness of SW-PBIS in improving the school climate (Bosworth \& Judkins, 2014), academic achievement (Freeman et al., 2015), and teacher wellbeing (Ross, Romer, \& Horner, 2012) as well as in reducing the frequency of behavior problems and disciplinary consequences for students (Childs, Kincaid, George, \& Gage, 2016; Horner et al., 2009). SW-PBIS has been studied across elementary, middle, and high school levels, in various settings, and for varying populations, with many positive results in regard to student behavior.

\section{SW-PBIS in Alternative Education Settings}

Numerous studies support the use of SW-PBIS in elementary and secondary schools in both urban and rural settings (e.g., Childs et al., 2016; Freeman et al., 2016) as well as juvenile justice (e.g., Sprague et al., 2013) and residential treatment settings (e.g., Swoszowski, McDaniel, Jolivette, \& Melius, 2013). Although some literature supports the implementation of 
SW-PBIS in the alternative school setting (e.g., Jolivette, McDaniel, Sprague, Swain-Bradway, \& Ennis, 2012; Simonsen \& Sugai, 2012), there remains limited research on the application of SW-PBIS in such settings.

Alternative school settings. Alternative schools are designed to provide specialized instruction to students who require more intensive support than can be offered in a traditional school. The Office of Juvenile Justice and Delinquency Prevention first supported the use of alternative education for delinquency prevention nearly 30 years ago (Garrison, 1987). Garrison posited that removing students from public schools and placing them in smaller, more supportive environments would provide them with a greater chance for success.

Alternative programs have been increasingly used as schools for youth with disruptive behaviors (Foley \& Pang, 2006). The findings of a national survey of alternative schools indicated that school districts reported physical aggression (52\%), chronic truancy (51\%), and verbal disruptive behavior (45\%) as the primary criteria for removal of a student from a regular education environment into an alternative school (Kleiner, Porch, \& Farris, 2002). This practice derives from the philosophy of alternative education as a place for disruptive or truant students, which is associated with stigma that continues to characterize many alternative education programs (Dunning-Lozano, 2016).

Impact of alternative school settings. Cox, Davidson, and Bynum (1995) conducted a meta-analysis of evaluations of 57 alternative education programs and found limited positive effects and methodological flaws associated with many of the studies. Similarly, Cox (1999) found that alternative programs had short-term effects on school attendance, grade point average, and self-esteem but that these effects were not present at a one-year follow-up. Although alternative schools are often characterized as "interventions," it is unclear which elements of 
these schools lead to positive outcomes for students. Because these settings tend to differ significantly in the services provided, behavior management systems, and general environment, it is difficult to determine which of these strategies have positive effects. Therefore, it is essential to evaluate the effects of specific programs and interventions used within alternative settings to evaluate what works for this population of students.

In an effort to begin to address the lack of research on PBIS intervention implementation in alternative schools, McDaniel, Jolivette, and Ennis (2014) studied the facilitators of and barriers to the implementation of SW-PBIS in the alternative school setting through the use of focus groups with staff from two separate alternative schools. The results indicated that successful implementation of SW-PBIS in the alternative school requires data-based decision making, initial and continued staff buy-in, adaptability in SW-PBIS interventions, and continued professional development and training. A case study by Gelbar, Jaffery, Stein, and Cymbala (2015), which considered the implementation of SW-PBIS in a K-12 clinical day treatment school for students with severe social-emotional and behavioral challenges, furthered this research. Due to the transient nature of the clinical day program population, the study was limited to just 20 students who attended the program for the entirety of the implementation year. Nevertheless, the researchers found that, in this setting, SW-PBIS led to the use of fewer physical restraints and incidents of seclusion of students.

Although studies have made inroads into understanding the efficacy of SW-PBIS in the alternative school setting, there are still gaps in the research. Thus, the current study sought to further this line of research by focusing on the adaptations used during the implementation of SW-PBIS in the alternative school setting and providing preliminary data on its effectiveness after one year of an SW-PBIS intervention. The current study took place in an alternative school 
on the central coast of California, administered by a county education office. The school was designed primarily for youth who had disciplinary or behavioral problems in regional district schools. Many students were involved in the juvenile justice system, had been expelled from their previous school for behavioral concerns, and required intensive behavioral and academic support. Given the intense needs of students in alternative schools, it is important to understand the challenges that exist when implementing systematic interventions.

\section{Challenges Related to PBIS in Alternative School Settings}

There are several barriers to consider when determining the interventions that work in the alternative school setting. Students enrolled in alternative schools have significantly higher rates of disabilities, mental health disorders, and antisocial behaviors than do those in the a comprehensive public school setting (Swain-Bradway, Swoszowski, Boden, \& Sprague, 2013). These factors, in combination with high student turnover and high intensity of behaviors, often lead to low student buy-in and high rates of punitive action by school staff (Lehr \& Lange, 2003; Swain-Bradway et al., 2013).

According to McDaniel et al. (2014), alternative schools face additional barriers in the form of staff buy-in, simultaneous implementation with pre-existing behavioral management systems, and increased demand to reward positive behaviors. With pre-existing behavioral management systems in place and high student turnover, there is a tendency to use punitive action rather to established positive behavioral goals and then to reward them. Because students in the alternative school setting display various levels of need, the demand on school staff to manage more difficult behaviors while also utilizing SW-PBIS procedures presents a barrier to staff buy-in and implementation fidelity. Staff and environmental factors, in addition to student- 
level factors, have led to limited research and mixed outcomes in regard to SW-PBIS in the alternative school setting.

\section{Current Study Rationale and Purpose}

SW-PBIS was developed to foster effective learning environments and encourage positive behaviors in all youth. Even with limited evidence of its effectiveness, the principles of SW-PBIS continue to be applied to the alternative school environment, as it is believed that the SW-PBIS framework could be a cost-effective resource in improving student behavior in this setting (Simonsen \& Sugai, 2013). Thus, this one-year case study was designed to examine the initial implementation of SW-PBIS in an alternative high school setting. The purpose of this study is twofold: (a) to identify ways in which the typical SW-PBIS model can be adapted to meet the needs of students in an alternative school setting, and (b) to evaluate the impact of an SW-PBIS model on discipline outcomes at an alternative education program in the initial implementation year.

\section{Method}

\section{Setting and Participants}

The present study involved students enrolled in an alternative community school on the central coast of California. The school serves students from Grades 7 through 12 who have had significant involvement in the juvenile justice system, are making the transition from a court school, or have been expelled from their district school. A total of 175 students were enrolled at the onset of the study, with an average enrollment of 155 students over the course of the school year. Given that the goal of alternative schools is to return students to their district school, and because there is high student involvement in the juvenile justice system, there was high turnover throughout the implementation year. As a result, 90 of the original 175 students enrolled at the 
onset of the study remained enrolled for more than 100 days. The school consisted of a $99 \%$ Latinx population, and $98 \%$ of students met the criteria for a free or reduced-price lunch. The school included students who (a) were expelled from their home school, (b) had externalizing and internalizing disorders, (c) had significant truancy problems, and (d) had been or were involved with the juvenile justice system. During the study, many of the students were affiliates or members of local gangs, and many had been exposed to some form of trauma (e.g., witnessed or experienced abuse).

Consent was obtained from students who were enrolled at the school at the onset of this project and as they were admitted. Of the students who provided consent, $23 \%$ were on formal probation and $67 \%$ were on informal probation. Of the participants, $68 \%$ identified as male and $32 \%$ as female. Participants ranged from 12 to 18 years old, and $74 \%$ of the students were between the ages of 15 and 17 . Further, $70 \%$ of the students were classified as English Language Learners, and $12 \%$ qualified for special education services.

\section{Measures}

School-wide Evaluation Tool (SET). The SET is used to measure the treatment integrity of SW-PBIS implementation efforts. Specifically, the SET can be used to assess training needs, personnel development efforts, and sustained use of SW-PBIS procedures as well as aid in the development of strategies for structuring outcomes (Horner et al., 2004). In this study, the SET was completed by the principal investigator prior to full implementation (Phase I) and following the first year of implementation (Phase III). The SET has high reliability (Cronbach's alpha = $.96)$, test-retest reliability $(97.3 \%)$, construct validity $(r=.75, p<.01)$, and sensitivity to change $(t=7.63, d f=12, p<.001 ;$ Horner et al., 2004). 
Effective Behavior Support (EBS) Survey. The EBS Survey was used to determine the level of implementation and priorities for change across school-wide, classroom, non-classroom, and individual levels. The EBS Survey can be completed by the entire staff or a smaller team and is used during the initial planning stage (Sugai, Horner, \& Todd, 2000). The EBS Survey was completed by the teaching staff and counseling staff prior to implementation (Phase I) and following the first year of implementation (Phase III).

Acknowledgments. One component of an SW-PBIS approach is the acknowledgment of appropriate behavior. In this study, students were given a ticket by the teaching staff that acknowledged the specific behavior observed when students displayed behaviors aligned with the identified behavioral expectations. These acknowledgements were entered into a drawing to win a reward. Tickets were printed on yellow paper, and the students fondly coined the term "golden tickets." The individual student acknowledgements ("golden tickets") given to students were collected by the school psychologist weekly, and the data were entered by the research team. Other research studies indicates that the number of tickets given to students is a broad and reliable indicator of the degree of participation in SW-PBIS by both teachers and students (Lassen, Steele, \& Sailor, 2006).

Incident reports. One of the most widely used measures used to determine effectiveness of SW-PBIS is the office discipline referral (ODR). Empirical evidence indicates that ODRs are a sensitive measure of the effects of interventions designed to change student behavior and to improve school climate (Irvin, Tobin, Sprague, Sugai, \& Vincent, 2004). Rather than ODRs, however, the alternative school in this study uses incident reports. Incident reports could be written by any staff member in the school for a variety of rule violations. Because rule violations recorded on the incident reports did not always lead to an ODR, use of the incident report as a 
behavioral measure provided information in regard to both the frequency and intensity of the behavior.

Incident report information was gathered by the principal investigator. Incident report data were coded by the principal investigator, using three behavior categories: (a) defiance, (b) delinquent behavior, and (c) physical altercations/threat of altercation. Defiance included general disregard toward school rules or teachers, disrespect toward staff, violation of "neutral territory," leaving school, and discussing sexual content. Delinquent behavior included drug or paraphernalia possession, being under the influence of a substance, property damage, stealing, and weapon possession. Physical altercation/threat involved threats made by students and student-on-student verbal or physical altercations. Data from the year prior to SW-PBIS implementation (Year 1) were collected to serve as a baseline, and data collected during the implementation year were used to compare school-wide outcomes of the initial implementation.

Classroom observation. Nelson, Colvin, and Smith (1996) found that changes in ODRs were similar to changes in direct observation data when used to measure students' social behavior, such as positive and negative social interactions. Few studies on SW-PBIS have used data from direct observations as measures of student and staff behavior. When observation data are used, they are often limited to hallways and playgrounds (Kern \& Manz, 2004).

Observations were conducted weekly in each classroom throughout the intervention year (Phase II). There were five classrooms in total, with each containing one core teacher (T1, T2, T3, T4, and T5) and two teacher's assistants (T1 TA1, T1 TA2, etc.) at all times. Three research assistants were identified by the primary investigator to assist in data collection in each classroom. All three research assistants had experience in observation techniques and data collection, and a training module was developed to provide an overview of the study, specific 
administration and scoring guidelines, and checks for accuracy. Prior to collecting observation data, research assistants collected sample data in the classroom until they obtained at least 95\% agreement with the principal investigator for two consecutive observations.

Prior to entering the classroom, the observer randomly selected two seat numbers and observed those students, using a custom BASC Portable Observation Program (BASC-POP) form. Observation intervals included a 12 -sec period, followed by a 3 -sec observation. The observer selected the appropriate button on the BASC-POP to indicate whether the student was on-task or off-task and whether the student was disruptive. Teacher-student interactions also were recorded during the entire interval and included positive, negative, or neutral interactions. Each observation lasted 30 minutes, and the percentages of on-task, off-task, and disruptive behaviors as well as positive, negative, and neutral interactions were calculated (Ern, 2007).

On-task behavior was defined as the student's attending to the teacher or assigned work (e.g., eyes oriented to teacher or work) and included both active and passive forms (e.g., looking at teacher lecturing, writing on worksheet). Off-task behavior included the student's not attending to assigned task. Disruptive behavior was any behavior that could disrupt students or the teacher, including academically unrelated verbal (e.g., call-outs, talking to students) or motoric (e.g., out-of-seat, throwing objects) behaviors. A broad category of disruptive behavior was selected to represent behaviors that typically elicit reprimands (e.g., out of seat, talking to peers).

Teacher-student interaction is defined through three categories: (a) positive, a praise statement following a student behavior; (b) neutral, statements that do not have a positive, negative, or instructional connotation; and (c) negative, a warning or negative response to student behavior. Teacher-student interactions were recorded with a frequency count per 
observation such that the percentage of positive, negative, and neutral comments made during the observation could be calculated.

During the implementation year, interobserver agreement was calculated for $16 \%$ of the observations by comparing the agreement (of the frequency count of each interaction category) between two independent observers. Sessions balanced by classroom and time of day were observed by two observers, and the interobserver agreement was calculated. The interobserver agreement across sessions ranged from $91.8 \%$ to $100 \%$, with an average agreement of $95.7 \%$.

\section{Research Design}

A case study approach was used to evaluate the program. Case studies have an exploratory nature and are used in a variety of situations to understand complex social phenomena in-depth (Gerring, 2007; Yin, 2014). This approach is particularly appropriate for the present applied research because it aims to understand the context and interpretation in a real world environment. Data collected in the present study, attempted to capture the case's uniqueness by thoroughly understanding and interpreting the program implementation in its unique context (Hammersley \& Gomm, 2000; Mills et al., 2010). In addition to a focus on intervention outcomes, this case study program evaluation allows us to study the process and to see how all parts of the program come together, and to gather in-depth data that could help identify the program's strengths and weaknesses (Green, 2011). Furthermore, program evaluation case studies can provide insights within the program, as well as for other programs with similar contexts (Mills et al., 2010). As with many case studies, this project was developed organically out of a community need.

Following, a conference presentation provided by the principal investigator (PI) on PBIS, the PI was approached by the school psychologist assigned to the alternative school. The school 
psychologist did not agree with the current discipline practices, as they were primarily focused on punitive measures and wanted to provide additional training to the principal and staff on more positive approaches to discipline. The PI and school psychologist worked collaboratively to develop a general plan for the case study and intervention implementation. The planned intervention was then implemented by the school psychologist with the support of the PI and trained graduate students.

Data were gathered using a combination of methods to evaluate the SW-PBIS implementation process and to obtain preliminary outcome indicators following the implementation year. A pre-post (AB) design was used to compare the effects of the intervention between baseline and implementation. Outcomes variables that existed prior to study implementation (e.g., incident reports) were compared at baseline (Year 1) and following one year of implementation (Year 2). Other data (e.g., classroom observation data) were collected at the onset of intervention implementation and were compared at onset (fall, Year 2) and at the end of the intervention year (summer, Year 2). Process data included the SET, EBS Survey, and acknowledgment data. Outcome data included incident reports and classroom observation data. Implementation of the project was divided into three phases, described below, and the timeframe, activity type, and activity description for each of the three phases are included in Tables $1-3$.

[Insert Tables 1-3 about here]

\section{Implementation Phases}

Phase I: Pre-intervention meetings and trainings. The first phase involved administrative pre-intervention meetings, teacher pre-intervention interviews, staff training and collaboration meetings, and alternative setting considerations. Each aspect is discussed below. 
Administrative pre-intervention meetings. The principal investigator conducted preimplementation meetings with the school psychologist, principal, and county education office representatives to discuss implementation details. Meetings were designed to answer questions, collaboratively develop an implementation strategy, and gain buy-in from key leadership.

Teacher pre-intervention interviews. All teachers were interviewed to identify concerns and current behavioral strategies and to establish a collaborative relationship. Questions included: (a) What behavior problems do you deal with most frequently in your classroom? (b) When dealing with inappropriate behavior, what strategies work? (c) What classroom/school rules are most important to you (crucial for classroom functioning)? and (d) What are students able to earn if they behave appropriately?

Staff training and collaboration meetings. Staff training and collaboration meetings were held weekly during the month prior to implementation. The principal investigator provided an overview of SW-PBIS and the importance of positive reinforcement, specifically with this population of students. Staff were asked to develop a customized form of SW-PBIS for their building. Teachers, teachers' assistants, and the principal worked collaboratively to establish school guidelines. Classroom teams (the teacher and two teacher assistants) were developed to ensure that staff were supporting one another in the implementation of the program.

Staff were encouraged to develop the school-wide intervention program. They decided on giving out "tickets" as a form of acknowledgment and having a weekly raffle. Students would enter their tickets in a box during their lunch period as a way to "take responsibility and ownership of the program." Staff were given examples of "tickets" and voted on a version to use. An acknowledgment system, in which students earned tickets when they displayed behaviors that aligned with school-wide guidelines, was developed. For example, if a student 
participated in class by answering questions, he or she would be given a ticket with his or her name on it, the staff would point out that they appreciate the student's participation, and the student would be reminded that he or she has a chance to win a prize. Through a collaborative approach, staff were involved in decision making at each step of the development of the intervention.

During the meetings, it was determined that teachers would work with students and teach them what each expectation means and "looks like" in the classroom. Teachers co-developed the scripted lessons plans and determined a time when all students could work on creating signs for classrooms and hallways that would "advertise" the guidelines. Following the collaboration meetings, staff members were trained by the principal investigator and school psychologist on the specifics of intervention implementation. SW-PBIS was maintained throughout the year through regular monthly trainings provided by the researchers and the school psychologist during staff meetings.

Alternative setting considerations. During Phase I, a number of areas were identified as important to address when working in the alternative school setting. The strategies implemented were central to achieving buy-in at the administrative, teacher, and student levels. Due to the typically punitive nature of this environment, additional time was spent working with teachers to identify their perspectives on discipline and to provide education and a framework related to positive discipline practices, including strategies to customize PBIS to their environment. Additionally, when art was created to reinforce the SW-PBIS guidelines, students were allowed to use their street-art skills (assuring no gang-affiliated tagging) and were encouraged to use their musical abilities to create hip-hop beats that reinforced the SW-PBIS guidelines. By allowing students to show their positive talents, teachers were able to gain buy-in 
from students and to create more excitement for the program while reinforcing the positive expectations.

Further, given the unique nature of the alternative school leadership structure, administrative buy-in was needed to reach beyond the school principal to include county administrators. Buy-in was sought early to highlight support across leadership levels and to demonstrate the significance of the proposed implementation of the SW-PBIS framework.

Phase II: Intervention and treatment integrity. The second phase involved the intervention and alternative setting considerations. Each is discussed below.

Intervention. Following the initial training and development of scripted lessons, each teacher taught students the new guidelines and explained the program. Lessons took approximately $45 \mathrm{~min}$ and were taught at the beginning of the semester during the same period in all classrooms. Refresher lessons, which outlined how the program worked, were implemented at the end and beginning of each semester. During the lesson, students were asked to define and discuss, provide examples of, and create posters for each guideline. The posters were placed around the school and served as constant reminders of the program. In addition, weekly lessons were provided on individual expectations. Refresher lessons on each guideline were provided one time a month, during staff meetings. On a monthly basis, teaching staff were provided with additional trainings on the SW-PBIS framework and allowed time to provide feedback and to troubleshoot any issues that came up during the month.

Throughout the year, students were acknowledged by the teaching staff for following the guidelines. In the collaboration meetings, it was decided that a minimum of three student acknowledgments would be distributed per day, per staff. Given the setting, it was hypothesized that students might be embarrassed and react negatively if publicly recognized. For this reason, 
students were given a small piece of yellow paper with a prepared statement, "I appreciate you for ...," and teachers filled in the specific praise. Examples include, "your hard work and helping out others in math" and "controlling your emotions even when others were not."

Students entered their tickets into a weekly drawing for prizes. During the students' lunch period on Fridays, teachers drew out two names per homeroom class. The teacher read aloud why the student earned the ticket (e.g., "Ivan won for reading in literature"), and the winning student drew a piece of paper from the "mystery motivator box" to find out their prize. Students could "gamble" their prize once but had to keep the second prize. School administrators surveyed students to find out what prizes would be reinforcing. Preferred food items and the ability to "pass" out of an assignment were highly preferred and valuable to earn in front of peers.

The number of acknowledgments (tickets) given per individual staff member and team per week were recorded, graphed, and provided to teachers weekly. Acknowledgements were graphed and organized by classroom team to encourage teamwork within the classrooms and to motivate one another to continue intervention implementation. The teaching team with the most acknowledgments given out to students for that week received a certificate and a prize.

These procedures were implemented in addition to current behavior management policies. The school principal requested that these policies remain in place throughout SW-PBIS implementation. The established policies involved teachers identifying a rule violation, determining if it was to be managed in the classroom or at the administrative level, completing an incident report, and handing the incident report to the principal. Based on the level of rule violation, previous violations, and the interventions available to the student (e.g., counseling, probation support) the principal would determine a consequence. Consequences ranged from 
removal from the classroom and placement in a highly supervised room to calling probation to report the incident. The consequence identified varied and was not implemented in a clear systematic way.

Alternative setting considerations. Students who attended this school tended to struggle with receiving positive feedback, particularly in public, as it could be considered detrimental to their "tough" image. Staff had hypothesized that students might be embarrassed and react negatively if publicly recognized. Therefore, a process of "stealth acknowledgment" was created, in which students were acknowledged discretely. It should be noted that, as the program progressed, students became more willing to be acknowledged publicly. It is possible that it became more apparent that the praise benefited students (they earned socially acceptable prizes) and became an integral part of the school culture. In addition, given the high level of turnover at the school, it is important to incorporate refresher lessons (on how the program works) more frequently to maintain momentum of the program. Although most of the teaching staff were motivated by the program and looked forward to the prizes, one of the teachers did not participate. This teacher stated that he would continue to use his current discipline strategies, despite the lack of positive response from students or administration. Future practices should consider the reinforcement of the teaching team and be sure that the rewards available are, in fact, reinforcing for a wide range of staff.

Phase III: The third phase involved data review and recommendations as well as alternative setting considerations. Each is discussed below.

Data review and recommendations. Behavioral data in the form of incident reports were collected throughout the academic year. Data were reviewed by the leadership team, and the team was provided monthly summary reports. These reports were shared at school-wide 
quarterly meetings. The format for these meetings included (a) presentation of data (incident reports, classroom observation data, and interviews with staff), (b) next steps in the action plan, and (c) the opportunity to provide feedback. Feedback was coded and organized by the principal investigator and included in monthly reports to the administration and research team.

Alternative setting considerations. Many of the staff meetings in these settings focus on recent crises and issues with significant behaviors, as staff are typically tired and at times "burnt out" (Williams, 2015). In addition to reminding staff of the importance of the intervention and sharing data, the researchers also worked to bring positivity to the meeting environment. This was done by encouraging discussion about positive incidents during the week, reinforcing staff who were following through with interventions, and encouraging staff to support one another.

\section{Results}

\section{Degree of SW-PBIS Implementation and Needs Evaluation}

School-wide Evaluation Tool (SET). Figure 1 provides a summary of the SET data by category and by total. The total mean score for the SET was examined in Year 1 (baseline) and Year 2 (implementation year). The results indicated that the percentage of critical components implemented in the school increased from $18 \%$ to $69 \%$ and that increases occurred in all categories except "system for responding to behavioral violations" and "district level support." It is important to note that because the alternative school in this study was supported by the county education office rather than by a local district, it functioned independently in regard to leadership and funding. For this reason, the overall score on the SET may be an underrepresentation of the true level of SW-PBIS implementation. When excluding "district level support," the mean score in this study is closer to $79 \%$ implementation. 
[Insert Figure 1 about here]

Staff perceptions of SW-PBIS. The EBS Survey provides a measure of the staff's perception of SW-PBIS at a particular moment in time and valuable information for program development and training purposes. The survey was used to measure staff perceptions related to SW-PBIS supports currently in place and future priorities. The data were then tallied and summarized. Using the summary data, the overall response of school staff for each system was displayed. Because this study focused primarily on the school-wide level of intervention, a test for significance was conducted for the school-wide component of the survey. A z-test was used to compare the proportion of responses that were "in place," "partially in place," and "not in place" with regard to the school-wide intervention from Year 1 (baseline) to Year 2 (intervention). The results indicated a change in the proportion of staff who rated school-wide components as "in place" from Year 1 to Year 2. In Year 1, 30\% of the ratings indicated schoolwide components as "in place," compared to 59\% in Year 2. A one-tailed z-test revealed a significant increase in ratings from Year 1 to Year $2(\mathrm{z}=2.5, \mathrm{p}<.05)$. Although there was a significant increase in the components that were considered to be "in place," there is still room for growth in this area. The summary data of the EBS was then used to help create an action plan for the following year.

Classroom observations. The 30 -minute classroom observations were analyzed to evaluate the impact of the intervention on classroom variables, including student behavior and student/teacher interactions. For each observation, the frequency of the target behaviors (ontask, off-task, and disruptive behavior; positive, negative, and neutral interactions) were reported. The results indicate the percentage of time that the particular behavior occurred in relation to other target behaviors. As SW-PBIS requires positively stated guidelines and rules for students, 
changes in positive components in the classroom over time, positive student-staff interactions, and on-task behavior were observed, rather than a reduction in off-task behavior.

Positive interactions. It was anticipated that, if the SW-PBIS framework positively affected school climate and teacher behavior, positive interactions between teachers and students would increase. For each month (total $=9$ ), the four observations per classroom were averaged to estimate the percentage of positive interactions observed in a particular month. The first three months (Time 1) and last three months (Time 2) were averaged to measure behavior change over time. There was no observed increase in positive interactions, other than a $1 \%$ increase for T5's class. Of the total behaviors recorded, the average percentages that were positive equaled $1 \%$ for T1's class, $2 \%$ for that of T2, 3\% for that of T3, and $4 \%$ for that of T4 (Table 4 ).

On-task behavior. On-task behavior is of particular importance in the classroom, as it is an indicator of student engagement in learning. The first three months (Time 1) and last three months (Time 2) were averaged to measure change over time. An overall increase in on-task behavior was observed between the first and second time points, with the exception of T4's class, which decreased from 51\% to 46\% (Table 4). On-task behavior for T1 increased from $64 \%$ to $71 \%$, T2 increased from $59 \%$ to $77 \%$, T3 increased from $53 \%$ to $74 \%$, and $\mathrm{T} 5$ increased from $50 \%$ to $59 \%$. T3's class had the largest increase in on-task behavior. It is of interest to note that this homeroom team gave out the most acknowledgments over the nine-month intervention period, perhaps indicating that increased positive reinforcement of expected behaviors with this population promotes an increase of on-task behaviors.

[Insert Table 4 about here]

Incident report data. Incident report data from Years 1 (baseline) and 2 (intervention) are an indicator of early behavioral outcomes. Although the population of the school is transient, 
the school admits students with a very similar history and behavioral profile. Thus, the overall change in incident reports provides an indication of how SW-PBIS could be affecting the culture of the school. The total number of incident reports for Year 1 was 733 and, for Year 2, 728. Overall, there was no significant reduction in incident reports during intervention. These data, however, are from the first year of implementation and are only an indicator of the progress made in the first year. One would expect to see a decline in incident reports after the program has been fully implemented over a number of years. In addition, because the population of students is transient, it is difficult to determine the impact of SW-PBIS in a short period of time.

Some differences were found in certain behaviors from Year 1 to Year 2. In Year 1, there were 500 incident reports (69\% of total) related to defiance compared to 451 (62\% of total) in Year 2, indicating a significant decrease in defiance-related incidents $(z=2.46, p<.05)$. Delinquent behavior significantly increased from 32 (4\% of total) in Year 1 to 53 (7\% of total) in Year $2(\mathrm{z}=2.46, \mathrm{p}<.05)$. Physical altercations and threats had a slight but nonsignificant increase $(\mathrm{z}=0.55, \mathrm{p}>.05)$, from $195(27 \%$ of total $)$ to 204 (28\% of total). Early implementation data indicate that, although there was an overall reduction in defiance-related incidents during the first year, there were slight increases in the other categories of behavior. Reductions in incident reports were noted in four of the nine months. August, the month with the largest decrease in incident reports from Year 1 to Year 2, was the month immediately following the establishment of the SW-PBIS rules and initial trainings. This is important to consider in such a program, as perhaps more frequent and consistent implementation of such trainings throughout the year would lead to more consistent positive outcomes.

\section{Discussion}


Although a body of research supports the use of SW-PBIS, few studies have evaluated the implementation and impact of SW-PBIS in alternative education settings. This study examined the initial implementation year of SW-PBIS in an alternative school and was designed to (a) identify ways in which the typical SW-PBIS models can be adapted to meet the needs of students in alternative school settings and (b) evaluate the early impact of the model on discipline outcomes at an alternative program in the initial implementation year.

\section{Adaptations for SW-PBIS in Alternative School Settings}

Buy-in. Buy-in can be a crucial component for the success of any PBIS intervention (e.g., Filter, Sytsma, \& McIntosh, 2016; Lohrman, Martin, \& Patil, 2013). It appears as though buy-in, at the administrator, teaching staff, and student levels, is especially important for the successful implementation of SW-PBIS in an alternative education setting.

Administrator and teaching staff buy-in. Given the unique infrastructure of many alternative schools, it is important to seek buy-in beyond the building principal. In this study, buy-in also was sought from administrators at the county education office. The building school psychologist was instrumental in obtaining buy-in at all levels, which helped to established trusting relationships with the administration and staff. Meeting with the school psychologist prior to team meetings was crucial in developing an acceptable plan of action and presenting a "united front" in terms of key aspects of the intervention. With the information provided by the research team, the school psychologist led many of the meetings. This step was important in obtaining resources and training time necessary for program implementation. Further, given the typically punitive nature of alternative school settings, it was important to focus on teaching staff buy-in and education before beginning implementation (Edgar-Smith \& Baugher Palmer, 2015; Lassen et al., 2006). This was established initially through trainings and workshops and 
maintained throughout the year via refresher courses. Another concern is related to teacher buyin within a small school. Sugai et al. (2005) suggest an $80 \%$ teacher buy-in prior to implementation. Given that students have some interaction with most teachers in a small school, they would likely be aware of teachers who do not participate in SW-PBIS and may interpret this negatively. One might consider that smaller schools need the commitment of every teacher to make a change.

Student buy-in. Students at an alternative school may be less inclined to show initial interest in a school-wide intervention program than are students in typical education settings (O’Brien \& Curry, 2009). Researchers worked with school staff to address potential barriers to participation and to develop ways to encourage involvement. In addition, a small group of students selected by the teachers helped in the initial development of expectations and reward options. The strategies included the "stealth acknowledgment" approach, a monthly reinforcer survey, and mystery motivators. The process of using of mystery motivators seemed to be motivating by itself (Robichaux \& Gresham, 2014). Further, students were encouraged to use their own unique artistic strengths, including street art and hip-hop beats, when creating artwork and music to reinforce the SW-PBIS guidelines. By allowing students to show their positive talents, teachers were able to gain buy-in from students and to create more excitement for the program, while reinforcing the positive expectations (Johnson, 2017).

Training. Training included teacher and staff training as well as student training. Each is discussed below.

Teacher and staff training. With the recognition that not all teachers and staff were participating fully in the SW-PBIS implementation, it could have been beneficial to include additional refresher trainings. These trainings, by focusing on barriers and facilitators to the SW- 
PBIS process, would allow teachers to provide feedback and ideas. Teachers who were having success could serve as models for their peers who had less success (McDaniel et al., 2014).

Student training. Given the high turnover at this alternative school, it is recommended that additional trainings on SW-PBIS take place throughout the year. Monthly or bi-monthly refresher lessons could maintain momentum among students. For students who transfer into the school midyear, it could be beneficial to create an onboarding lesson as part of the orientation to the school. For example, future intervention projects could consider a "New Student Welcome Program" that would help to introduce and reinforce SW-PBIS concepts to the students as they enter as well as create opportunities for current students to provide mentorship and demonstrate their knowledge and experience with the program.

Office disciplinary referrals/incident reports. In compliance with school policy, teachers were asked to complete an incident report any time that a student violated a school rule. Similar to ODRs, incident reports are subject to variation, dependent on the teacher, the teacher's tolerance level that day, and the teacher's relationship with the student involved (Gage, Larson, Sugai, \& Chafouleas, 2016). Given the teacher-dependent factors, measuring only the absence of problem behaviors might not provide a complete picture. The impact of SW-PBIS was not necessarily observed in the number of ODRs but, rather, could be seen symbolically around the school (e.g., students asking to earn tickets, teachers getting excited about the process). Perhaps the effects of SW-PBIS at this school were to increase student and staff involvement and creativity in the process of implementing the program. Future research may need to consider how to best capture these positive effects.

Resource allocation and sustainability. Given the outcomes of the present study following one year of implementation and the amount of time invested in developing and 
implementing the SW-PBIS framework, one might ask: Is it worth it? Knowing that research suggests that it can take three to five years of SW-PBIS implementation to show significant results (Bohanon et al., 2006; Harms, 2010), there is a need to consider whether the results of the current study are significant enough to warrant continued investment of resources. Although the time investment may decrease as the program becomes more established, initial time investment included 2,364 hours of personnel time (e.g., planning, data collection, observations) and 39 hours of meetings (e.g., planning, trainings). Schools may need to quantify the outcome that would deliver an appropriate return on investment.

It is also important to have a sustainability plan (Johnson, 2014). Although the first years of implementation has a heavier workload than the subsequent year, there remains a continued need for support. In this project, a number of supports were in place to help with sustainability. Researchers worked closely with administration to ensure that teachers were given time to attend trainings and to create materials. The school psychologist collaborated with the investigators so that the project could be led by the special education team and designated a portion of the intern's assignment to include SW-PBIS support. Further, in collaboration with a local school psychology training program, the sehool psychologist offered opportunities for graduate students to gain experience in this setting while collecting data and supporting implementation.

Practitioners should consider the community partners, such as individuals at a local university level, who are willing and able to collaborate on creating a sustainable intervention program.

\section{Implementation}

In the present study, the SET data indicated an increase in the number of SW-PBIS components implemented in the school during the one-year period. Use of the SET data alone indicated a significant increase in SW-PBIS components, but there remains room for 
improvement. Given that this is the first implementation year, the increase in SW-PBIS appears to be on track, but the team will continue to focus on areas that did not meet $80 \%$ implementation.

The results did not yield significant differences in overall problem behavior (incident reports) when compared to the year prior. This is consistent with research that notes that, until full implementation occurs, it can take years before an SW-PBIS model stabilizes (Harms, 2010). There was, however, an overall reduction in defiance-related incidents, which may speak to the limits of SW-PBIS. The program included teaching and reinforcement of appropriate behaviors, but perhaps this intervention cannot be expected to make a significant impact on serious behaviors (delinquent, verbal/physical altercation), or it may take longer for SW-PBIS to generalize, as earlier research indicates. Further, it may be important to develop a measure that is more sensitive to change over time and considers additional ways to measure positive changes in student outcomes.

\section{Limitations}

This study was conducted in one alternative school with five core teachers. A total of 173 students were used in the school-wide data analyses. A limitation inherent in this particular sample is the inability to generalize to the greater population. These students are primarily Latinx, and over $90 \%$ receive a free or reduced-price lunch. Further, participants could not be randomly selected, as they were enrolled in the alternative school, and they differ systematically from those who were not enrolled. Thus, the results will likely not generalize to typical youth and are more reflective of students on the periphery of school engagement. Nevertheless, such information is crucial to obtain. 
The lack of a control school prevents the drawing of conclusions regarding effectiveness of SW-PBIS in alternative schools. A reduction in problem behaviors may not necessarily reflect an increase in positive behaviors. When looking at school-wide outcomes, we note that another limitation is the comparison of data across different cohorts, as there is a large turnover in this population, and a comparison of students from Year 1 to Year 2 is not ideal. Although observations of positive classroom behaviors are crucial to understanding intervention impact, outcome data in these categories showed little change. This lack of change may be explained by the transient nature of the school population, providing limited time to build positive relationships with some students. As SW-PBIS requires several years before full implementation, it is expected that the overall climate would shift and positive interactions would increase over time as teachers gain additional experience with positively reinforcing prosocial behaviors rather than punishing student misbehavior. Another consideration for future studies, is that the observations began at the onset of implementation, and change may not have been detected because positive interactions may have been strongest at the beginning of intervention implementation and reduced over time. Future studies should focus on collecting this data prior to implementation, in order to get a better sense of impact.

This study involved extensive researcher involvement in terms of hours, indicating that alternative schools may need a greater allocation of resources in the planning and initial implementation stages of SW-PBIS. Researcher involvement extended to some of the data collection process as well. Because the researchers had extensive involvement with the school team, the SET was completed by the principal investigator, potentially leading to investigator bias. Despite the extensive hours expended by the research team, four elements of the SET remained below the $80 \%$ level of implementation ("system for responding to behavioral 
violations," "district level support," "monitoring and evaluation," and the total score). Despite some lower levels of implementation, however, the critical components of the SET increased from $18 \%$ to $69 \%$ implementation. As noted earlier, the school was supported by a county education office, rather than a local district, and functioned relatively independently in regard to leadership and funding. For this reason, the overall score on the SET may be an underrepresentation of the true level of SW-PBIS implementation. When "district level support" was excluded, the mean score was closer to $79 \%$ implementation.

One of the unique factors in the alternative school setting is that there are often preexisting behavior management policies. In this case, the school principal requested that these policies remain in place throughout SW-PBIS implementation. Although it was expected that implementation fidelity would increase over time as existing policies are phased out, the system for responding to behavior violations did not change across the implementation year.

\section{Future Directions}

Ideally, SW-PBIS could be implemented in multiple alternative schools and in randomly chosen control schools. Further, it would be useful to implement SW-PBIS with additional components that address the specific needs of the alternative education population (e.g., mental health services, trauma-informed practices). When working with students who have been exposed to trauma, such as gang violence, SW-PBIS is an essential component in creating a safe and supportive school (Dorado, Martinez, McArthur, \& Leibovitz, 2016). In addition, in combination with training in trauma-informed practices, SW-PBIS can help to promote safety, predictability, social emotional learning, and dependable relationships (Mirsky, 2011). Future programs may embed professional development on trauma and trauma-informed services into the SW-PBIS trainings. This includes definitions, prevalence, types of trauma, and signs to look for 
in and out of the classroom. These trainings provide a community of staff and students who understand the impacts of trauma, recognize the signs, and respond appropriately. Additionally, trauma-informed schools provide a strong sense of physical and emotional safety. Beyond providing a trauma-informed community of staff and students, specific strategies, taught in the guided lesson plans, can help youth recognize and manage emotions, set and achieve goals, establish and maintain relationships, and make responsible decisions. Together, these efforts can facilitate academic engagement, work ethic, commitment, and overall school success (Durlak et al., 2011). When children feel safe at school and have the tools to cope with their trauma, they show better academic, behavioral, and social outcomes (Chafouleas et al., 2016).

The inclusion of a parental involvement component might provide additional support to teachers and students. García Coll and Garrido (2000) suggest that culturally and linguistically appropriate services should be applied in the school setting to facilitate parental participation.

Given that many of these students have unmet basic needs (e.g., safety, substance use problems), it is important for practitioners and researchers to consider the impact of such needs on behaviors and related outcomes. For example, the possibility of earning a preferred snack at a golden ticket drawing would not outweigh the safety need of a student who brings a weapon to school. It is possible that positive changes are occurring due to the intervention but are not being captured by the current measures used (i.e., observations of positive interactions, on-task behavior). Given this, there is also a need for more data on both student and teacher perceptions and a direct measure of the overall school climate. Perhaps including a periodic measure of the school climate might provide insight into how it is being affected by the intervention. As this was the first year of the study, it will be important to continue tracking data at this school to determine whether continued years of intervention have an impact on school-wide and individual 
student outcomes. In addition, measures of positive behaviors (e.g., on-task behavior, positive interactions) should be collected prior to and throughout implementation.

\section{Concluding Remarks}

This study offers continued support for utilizing SW-PBIS in what is typically considered a punitive environment. Although significant growth was not achieved across all measures, it is important to remember that it can take several years before SW-PBIS yields a full positive effect. Given the initial response, however, it is believed that SW-PBIS could be a promising evidencebased framework in alternative schools. That said, there remains room for growth and continued research. It is important to recognize that the students in this study exhibit more extreme behaviors than those typically observed in students in mainstream schools. For this reason, it may take longer before a decrease in negative behaviors and an increase in positive behaviors are observed, particularly at the Tier 1 level. At the current implementation stage, it is important to focus on the process and potential rather than solely on the outcomes. Further work could develop a model for applying SW-PBIS in alternative school settings. 


\section{Compliance with Ethical Standards}

All procedures performed in studies that involve human participants were in accordance with the ethical standards of the institutional and/or national research committee and with the 1964 Helsinki declaration and its later amendments or comparable ethical standards. Informed consent was obtained from all individual participants included in the study. 


\section{References}

Abry, T., Bryce, C. I., Swanson, J., Bradley, R. H., Fabes, R. A., \& Corwyn, R. F. (2017).

Classroom-level adversity: Associations with children's internalizing and externalizing behaviors across elementary school. Developmental Psychology, 53, 497-510. doi:10.1037/dev0000268

Bohanon, H., Fenning, P., Carney, K. L., Missis-Kim, M. J., Anderson-Harriss, S., Moroz, K. B., ... Pigott, T. D. (2006). School-wide application of positive behavior support in an urban high school: A case study. Journal of Positive Behavior Interventions, 8, 131-145. doi:10.1177/10983007060080030201

Bosworth, K., \& Judkins, M. (2014). Tapping into the power of school climate to prevent bullying: One application of schoolwide positive behavior interventions and supports. Theory into Practice, 53, 300-307. doi:10.1080/0040505841.2014.947224

Burke, M. D., Davis, J. L., Hagan-Burke, S., Lee, Y. H., \& Fogarty, M. S. (2014). Using SWPBS expectations as a screening tool to predict behavioral risk in middle school. Journal of Positive Behavior Interventions, 16, 5-17. doi:10.1177/1098300712461147

Chafouleas, S. M., Johnson, A. H., Overstreet, S., \& Santos, N. M. (2016). Toward a blueprint for trauma-informed service delivery in schools. School Mental Health, 8, 144-162. Advance online publication. doi:10.1007/s12310-015-9166-8

Childs, K. E., Kincaid, D., George, H. P., \& Gage, N. A. (2016). The relationship between school-wide implementation of positive behavior intervention and supports and student discipline outcomes. Journal of Positive Behavior Interventions, 18, 89-99. doi:10.1177/1098300715580992 
Cohen, J. (2006). Social, emotional, ethical and academic education: Creating a climate for learning, participation in democracy and well-being. Harvard Educational Review, 76, 201-237. doi:10.17763/haer.76.2.j44854x1524644vn

Cook, C. R., Williams, K. R., Guerra, N. G., Kim, T. E., \& Sadek, S. (2010). Predictors of bullying and victimization in childhood and adolescence: A meta-analytic investigation. School Psychology Quarterly, 25, 65-83. doi:10.1037/a0020149

Cox, S. M. (1999). An assessment of an alternative education program for at-risk delinquent youth. Journal of Research in Crime and Delinquency, 36, 300-322. doi:10.1177/0022427899036003004

Cox, S. M., Davidson, W. S., \& Bynum, T. S. (1995). A meta-analytic assessment of delinquency-related outcomes of alternative education programs. Crime and Delinquency, 41, 219-234. doi: 10.1177/0011128795041002004

Dorado, J. S., Martinez, M., McArthur, L. E., \& Leibovitz, T. (2016). Healthy environments and response to trauma in schools (HEARTS): A whole-school, multi-level, prevention and intervention program for creating trauma-informed, safe and supportive schools. School Mental Health, 8, 163-176. doi:10.1007/s12310-016-9177-0

Dunning-Lozano, J. L. (2016). Race and opportunity in a public alternative school. Race, Ethnicity, and Education, 19, 433-460. doi:10.1080/13613324.2014.91116

Durlak, J. A., Weissberg, R. P., Dymnicki, A. B., Taylor, R. D, \& Schellinger, K. B. (2011). The impact of enhancing students social and emotional learning: A metal analysis of schoolbased universal interventions. Child Development, 82, 405-432. doi:10.1111/j.14678624.2010.01564.x 
Eagle, J. W., Dowd-Eagle, S. E., Snyder, A., \& Gibbons Holtzman, E. (2015). Implementing a multi-tiered system of supports (MTSS): Collaboration between school psychologists and administrators to promote systems-level change. Journal of Educational \& Psychological Consultation, 25, 160-177. doi:10.1080/10474412.2014.929960

Edger-Smith, S., \& Baugher Palmer, R. (2015). Building supportive school environments for alternative education youth. Preventing School Failure, 59, 134-141. doi:10.1080/1045988X.2013.86558

Ern, G. S. (2007). An examination of the relationship between the presence of critical components of classroom positive behavior support and student behavior. Dissertation Abstracts International Section A: Humanities and Social Sciences, 67, 2878.

Filter, K. J., Sytsma, M., \& McIntosh, K. (2016). A brief measure of staff commitment to implement school-wide positive behavioral interventions and supports. Assessment for Effective Intervention, 42, 18-31. doi:10.11772F1534508416642212

Freeman, J., Simonsen, B., McCoach, B. D., Sugai, G., Lombardi, A., \& Horner, R. (2016). Relationship between school-wide positive behavior interventions and supports and academic, attendance, and behavior outcomes in high schools. Journal of Positive Behavioral Interventions, 18, 41-51. doi:10.1177/1098300715580992

Foley, R. M., \& Pang, L. S. (2006). Alternative education programs: Program and student characteristics. The High School Journal, 89, 10-21. doi:10.1353/hsj.2006.0003

Gage, N. A., Larson, A., Sugai, G., \& Chafouleas, S. M. (2016). Student perceptions of school climate as predictors of office discipline referrals. American Educational Research Journal, 53, 492-515. doi:10.3102/000281216637349 
García Coll, C. T., \& Garrido, M. (2000). Minorities in the U.S.: Sociocultural context for mental health and developmental psychopathology. In M. Lewis \& A. Sameroff (Eds.), Handbook of developmental psychopathology (2nd ed., pp. 177-195). New York, NY: Kluwer Academic/Plenum.

Garrison, R. W. (1987) Alternative schools for disruptive youth: NSSC resource paper. Malibu, CA: National Safety Center, Pepperdine University, Office of Juvenile Justice and Delinquency Prevention. doi:10.1177/0022427899036003004

Gelbar, N. W., Jaffery, R., Stein, R., \& Cymbala, H. (2015). Case study on the implementation of school-wide positive behavior intervention and supports in an alternative educational setting. Journal of Educational and Psychological Consultation, 25, 287-313. doi:10.1080/10473312.2014.929958

Gerring, J. (2007). Case study research: Principles and practices. New York, NY: Cambridge University Press.

Green, R. A. (2011). Case study research: A program evaluation guide for librarians. Santa Barbara, CA: Libraries Unlimited.

Hammersley, M., \& Gomm, R. (2000). Introduction. In R. Gomm, M. Hammersley, \& P. Foster (Eds.), Case study method (pp.1-16). Thousand Oaks, CA: Sage.

Harms, A. L. S. (2010). A three-tier model of integrated behavior and learning supports: Linking system-wide implementation to student outcomes. Retrieved from ProQuest Information \& Learning. (AAI3433110)

Horner, R., Sugai, G., Smolkowski, K., Todd, A., Nakasato, J., \& Esperanza, J. (2009). A randomized control trial of school-wide positive behavior support in elementary 
schools. Journal of Positive Behavior Interventions, 11(3), 113-144.

doi:10.1177/1098300709332067

Horner, R. H., Todd, A. W., Lewis-Palmer, T., Irvin, I. K., Sugai, G., \& Boland, J. B. (2004).

The school-wide evaluation tool (SET): A research instrument for assessing school-wide positive behavior support. Journal of Positive Behavior Interventions, 6, 3-12. doi:10.1177/10983007040060010201

Irvin, L., Tobin, T., Sprague, J. R., Sugai, G., \& Vincent, G. (2004). Validity of office discipline referrals measures as indices of school-wide behavioral status and effects of school-wide behavioral interventions. Journal of Positive Behavior Interventions, 6, 34-52. doi: $10.1177 / 10983007040060030201$

Johnson, E. B. (2017). Beliefs on behavior: The influence of constructed beliefs of discipline on school-wide positive behavior interyentions and supports fidelity of implementation. Dissertation Abstracts International Section A: Humanities and Social Sciences, 78, 5A.

Johnson, J. P. (2014). Sustaining positive behavior intervention and support. Retrieved from ProQuest Information \& Learning. (ED569105)

Jolivette, K., McDaniel, S. C., Sprague, J., Swain-Bradway, J., \& Ennis, R. P. (2012). Embedding the positive behavioral interventions and supports framework into the complex array of practices within alternative education settings: A decision-making process. Assessment for Effective Intervention, 38, 15-29. doi:10.1177/153450841254450

Kauffman J. M., \& Brigham, F. J. (2009). Working with troubled children. Verona, WI: Attainment.

Kern, L., \& Manz, P. (2004). A look at current validity issues of school-wide behavior support. Behavioral Disorders, 30, 47-59. doi:10.1177/019874290403000102 
Kincaid, D., Dunlap, G., Kern, L., Lane, K. L., Bambara, L. M., Brown, ... Knoster, T. P. (2016). Positive behavior support: A proposal for updating and refining the definition. Journal of Positive Behavior Interventions, 18, 69-73. doi:10.1177/1098300715604826

Kleiner, B., Porch, R., \& Farris, E. (2002). Public alternative schools and programs for students at risk of education failure: 2000-01 (NCES 2002-004). Washington, DC: U.S. Department of Education National Center for Education Statistics.

Lassen, S. R., Steele, M. M., \& Sailor, W. (2006). The relationship of school-wide positive behavior support to academic achievement in an urban middle school. Psychology in the Schools, 43, 701-712. doi:10.1002/pits.20177

Lehr, C. A., \& Lange, C. M. (2003). Alternative schools and the students they serve: Perceptions of state directors of special education. Policy Research Brief, 14(1). Minneapolis, MN: Institute on Community Integration.

Lohrman, S., Martin, S. D., \& Patil, S. (2013). Internal and external coaches' perspectives about overcoming barriers to universal interventions. Journal of Positive Behavior Interventions, 15, 26-38. doi:10.1177/1098300712459078

McDaniel, S. C., Jolivette, K., \& Ennis, R. P. (2014) Barriers and facilitators to integrating SWPBIS in alternative education settings with exiting behavior management systems. Journal of Disability Policy Studies, 24, 247-256. doi:101177/1044207312465471

Mills, A. J., Durepos, E., \& Wiebe, E. (Eds.). (2010). Encyclopedia of case study research (Vols. 1-2). Thousand Oaks, CA: SAGE.

Mirsky, L. (2011). Restorative practices: Giving everyone a voice to create safe saner school communities. The Prevention Researcher, 18, 3-6. Available from, https://www.iirp.edu/images/pdf/Mirsky-Prevention-Researcher-2011.pdf 
Nelson, J. R., Colvin, G., \& Smith, D. J. (1996). The effects of setting clear standards on students' social behavior in common areas of the school. The Journal of At-Risk Issues, 3(1), 10-19. doi:10.1177/106342669800600303

O’Brien, E. R., \& Curry, J. R. (2009). Systematic interventions with alternative school students: Engaging the omega children. Journal of School Counseling, 7, 1-32. EJ886138

Ogulmus, K., \& Vuran, S. (2016). Schoolwide positive behavioral interventions and support practices: Review of studies in the Journal of Positive Behavior Interventions. Educational Sciences: Theory \& Practice, 16, 1693-1710. doi:10.12738/estp.2016.5.0264

Positive Behavioral Interventions \& Supports. (n.d.). School-wide Positive Behavioral Interventions and Supports. Retrieved from http://www.pbis.org/

Robichaux, N. M., \& Gresham, F. M. (2014). Differential effects of the mystery motivator intervention using student-selected and mystery rewards. School Psychology Review, 43, $286-298$.

Ross, S. W., Romer, N., \& Horner, R. H. (2012). Teacher well-being and the implementation of School-Wide Positive Behavior Interventions and Supports. Journal of Positive Behavioral Supports, 14, 118-128. doi:10.1177/1098300711413820

Simonsen, B., \& Sugai, G. (2013). PBIS in alternative education settings: Positive support for youth with high-risk behavior. Education and Treatment of Children, 36, 3-14. Available from https://www.pbis.org/Common/Cms/files/pbisresources/ETC2013SpecialIssue.pdf Sprague, J. R., Scheuermann, B., Wang, E., Nelson, C. M., Jolivette, K., \& Vincent, C. (2013). Adopting and adapting PBIS for secure juvenile justice settings: Lessons learned. Education and Treatment of Children, 36, 121-134. EJ1014473 
Sugai, G., \& Horner, R. H. (2009). Defining and describing school-wide positive behavior support. In W. Sailor, G. Dunlap, G. Sugai, \& R. H. Horner (Eds.), Handbook of positive behavior support (pp. 307-326). New York, NY: Springer.

Sugai, G., Horner, R. H., \& Todd, A. W. (2000). Effective behavior support: Self-assessment survey. Eugene, OR: University of Oregon, Positive Behavioral Interventional and Supports Technical Assistance Center.

Sugai, G., Horner, R. H., Sailor, W., Dunlap, G., Eber, L., Lewis, T., ... Nelson, M. (2005). School-wide positive behavior support: Implementers' blueprint and self-assessment. Eugene, OR: University of Oregon.

Swain-Bradway, J., Swoszowski, N. C., Boden, L. J., \& Sprague, J. R. (2013). Voices from the field: Stakeholder perspectives on PBIS implementation in alternative education settings. Education and Treatment of Children, 36, 31-46. EJ1014492

Swoszowski, N. C., McDaniel, S. C., Jolivette, K., \& Melius, P. (2012). The effects of Tier II check-in/check-out, including adaptation for non-responders on the off-task behavior of elementary students in a residential treatment facility. Education and Treatment of Children, 36, 63-80. EJ1014499

Williams, J. (2015). Juvenile correctional educators' perceptions of satisfaction with their role as alternative school educators. Dissertation Abstracts International, 75, 12-A.

Yin, R. K. (2014). Case study research: Design and methods (5th ed.). Los Angeles, CA: Sage. 
Table 1

Pre-Implementation: Year 1 (Baseline) Process

\begin{tabular}{|c|c|c|}
\hline Timeframe & Activity Type & Activity Description \\
\hline 1x quarterly & $\begin{array}{l}\text { Administration pre- } \\
\text { intervention meetings }\end{array}$ & $\begin{array}{l}\text { Met with school psychologist, principal, key county } \\
\text { representatives, and university faculty } \\
\text { Provided overview of potential benefits/outcomes } \\
\text { Discussed implementation details } \\
\text { Developed a process for troubleshooting issues }\end{array}$ \\
\hline $\begin{array}{l}1 \mathrm{x} \text { (prior to pre- } \\
\text { intervention } \\
\text { trainings) }\end{array}$ & $\begin{array}{l}\text { Teacher pre-intervention } \\
\text { interviews }\end{array}$ & $\begin{array}{l}\text { Interviewed teachers to identify behavioral concerns } \\
\text { Established collaborative relationship by asking } \\
\text { questions related to useful and acceptable strategies }\end{array}$ \\
\hline 1x monthly & $\begin{array}{l}\text { Teaching staff pre- } \\
\text { intervention/collaboration } \\
\text { meetings }\end{array}$ & $\begin{array}{l}\text { Held staff training and collaboration meetings } \\
\text { Provided an overview of School-Wide Positive } \\
\text { Behavioral Interventions and Supports (SW-PBIS) } \\
\text { Taught importance of using positive reinforcement with } \\
\text { this population } \\
\text { Encouraged culture/climate of positivity through } \\
\text { trainings and support }\end{array}$ \\
\hline $\begin{array}{l}\text { 1x weekly (one } \\
\text { month prior to } \\
\text { implementation) }\end{array}$ & $\begin{array}{l}\text { Teaching staff program } \\
\text { development meetings }\end{array}$ & $\begin{array}{l}\text { Developed a customized form of SW-PBIS } \\
\text { Established guidelines } \\
\text { Co-developed scripted lesson plans }\end{array}$ \\
\hline 1x monthly & Teaching staff trainings & $\begin{array}{l}\text { Principal investigator and school psychologist trained } \\
\text { teaching staff on specifics of intervention implementation } \\
\text { SW-PBIS was maintained through regular training by the } \\
\text { researchers during meetings with teachers and the } \\
\text { administrator. }\end{array}$ \\
\hline $\begin{array}{l}\text { 1x (one month } \\
\text { prior to } \\
\text { implementation) }\end{array}$ & $\begin{array}{l}\text { Data collection: School } \\
\text { Evaluation Tool (SET) }\end{array}$ & $\begin{array}{l}\text { SET was used to assess training needs, impact of } \\
\text { personnel development efforts in SW-PBIS areas, and } \\
\text { sustained use of SW-PBIS procedures, and to develop } \\
\text { strategies for structuring outcomes }\end{array}$ \\
\hline $\begin{array}{l}1 \mathrm{x} \text { (one month } \\
\text { prior to } \\
\text { implementation) } \\
\text { 1x monthly }\end{array}$ & $\begin{array}{l}\text { Data collection: Effective } \\
\text { Behavior Support (EBS) } \\
\text { Survey } \\
\text { Data collection: Incident } \\
\text { report data from Year } 1\end{array}$ & $\begin{array}{l}\text { EBS Survey was used to determine the level of } \\
\text { implementation and priority for change } \\
\text { Gathered incident report data } \\
\text { Entered and coded incident report data }\end{array}$ \\
\hline
\end{tabular}


Table 2

Intervention: Year 2 (Implementation) Process

\begin{tabular}{|c|c|c|}
\hline Timeframe & Activity Type & Activity Description \\
\hline $\begin{array}{l}\text { First and last week } \\
\text { of each semester } \\
\text { 1x monthly }\end{array}$ & $\begin{array}{l}\text { Lesson plan regarding school } \\
\text { guidelines and program specifics } \\
\text { Lesson plan "refresher" sessions } \\
\text { on specific guidelines }\end{array}$ & $\begin{array}{l}\text { Classroom teacher taught/re-taught students the } \\
\text { guidelines and explained how the program worked } \\
\text { Classroom teacher taught/re-taught students each } \\
\text { guideline, using scripted lesson plans } \\
\text { Students learned to define behavioral guidelines } \\
\text { (providing examples and non-examples) } \\
\text { Students created posters/art/hip hop beats for each } \\
\text { guideline and displayed them in the school }\end{array}$ \\
\hline 1x monthly & Reinforcer selection & $\begin{array}{l}\text { Surveyed students to determine preferred prizes } \\
\text { Created a class-wide list of preferred prizes }\end{array}$ \\
\hline Daily & Acknowledgments given & $\begin{array}{l}\text { Students were acknowledged by the teaching staff for } \\
\text { following school-wide guidelines }\end{array}$ \\
\hline 1x weekly & Reinforcer distribution & $\begin{array}{l}\text { Held weekly drawings for prizes } \\
\text { Two students per class were selected and } \\
\text { acknowledged } \\
\text { Winning students selected mystery motivator prize }\end{array}$ \\
\hline 1x monthly & Staff training "refresher" & $\begin{array}{l}\text { Provided additional information about structure of SW- } \\
\text { PBIS } \\
\text { Discussed issues that needed troubleshooting } \\
\text { Reinforced importance of using positive reinforcement } \\
\text { Encouraged culture/climate of positivity through } \\
\text { trainings and support }\end{array}$ \\
\hline 1x weekly & & $\begin{array}{l}\text { Graphed number of acknowledgements, per individual } \\
\text { staff member, per week } \\
\text { Graphed number of acknowledgements by team } \\
\text { Provided graphed performance feedback in staff } \\
\text { meetings } \\
\text { High-performing teaching staff received an } \\
\text { acknowledgement and a prize }\end{array}$ \\
\hline $1 \mathrm{xw}$ & tion: classroom & $\begin{array}{l}\text { Observed student-teacher interactions } \\
\text { Frequency of the target behaviors (on-task, off-task, } \\
\text { and disruptive behavior; as well as positive, negative, } \\
\text { and neutral interactions) were collected }\end{array}$ \\
\hline & $\begin{array}{l}\text { Data collection: } \\
\text { acknowledgment data }\end{array}$ & $\begin{array}{l}\text { Collected and graphed number of acknowledgments } \\
\text { given to students by staff member }\end{array}$ \\
\hline 1x monthly & $\begin{array}{l}\text { Data collection: incident report } \\
\text { data from Year } 2\end{array}$ & $\begin{array}{l}\text { Gathered incident report data } \\
\text { Entered and coded incident report data } \\
\text { Shared data in school-wide quarterly meetings and } \\
\text { solicited feedback on process }\end{array}$ \\
\hline
\end{tabular}


Table 3

Post-Implementation (of First Year): Data Collection Process

\begin{tabular}{lll}
\hline Timeframe & Activity Type & Activity Description \\
\hline $\begin{array}{l}\text { 1x last month of } \\
\text { intervention year }\end{array}$ & $\begin{array}{l}\text { Data collection: School-wide } \\
\text { Evaluation Tool (SET) }\end{array}$ & $\begin{array}{l}\text { SET used to assess training needs, impact of } \\
\text { personnel development efforts in School-Wide } \\
\text { Positive Behavioral Interventions and Supports } \\
\text { (SW-PBIS) areas, and sustained use of SW-PBIS } \\
\text { procedures and to develop strategies for structuring } \\
\text { outcomes }\end{array}$ \\
$\begin{array}{ll}\text { 1x last month of } \\
\text { intervention year }\end{array}$ & $\begin{array}{l}\text { Data collection: Effective Behavior } \\
\text { Support (EBS) Survey }\end{array}$ & $\begin{array}{l}\text { EBS Survey used to determine the level of } \\
\text { implementation and priority for change }\end{array}$ \\
\hline
\end{tabular}


Table 4

Classroom Observations

\begin{tabular}{lrrrrrrrr}
\hline & \multicolumn{2}{c}{ Positive Interactions } & & & \multicolumn{3}{c}{ Percentage of Time On-Task } \\
\cline { 2 - 4 } Classroom & Time 1 & Time 2 & Slope & & Time 1 & Time 2 & \multicolumn{2}{c}{ Slope } \\
\hline T1 & $1 \%$ & $1 \%$ & 0 & & $64 \%$ & $71 \%$ & 1.25 \\
T2 & $2 \%$ & $2 \%$ & 0.14 & & $59 \%$ & $77 \%$ & 1.15 \\
T3 & $3 \%$ & $3 \%$ & -0.22 & & $53 \%$ & $74 \%$ & 3.21 \\
T4 & $4 \%$ & $4 \%$ & 0.14 & & $51 \%$ & $46 \%$ & -0.62 \\
T5 & $2 \%$ & $3 \%$ & -0.46 & & $50 \%$ & $59 \%$ & 1.15 \\
\hline
\end{tabular}




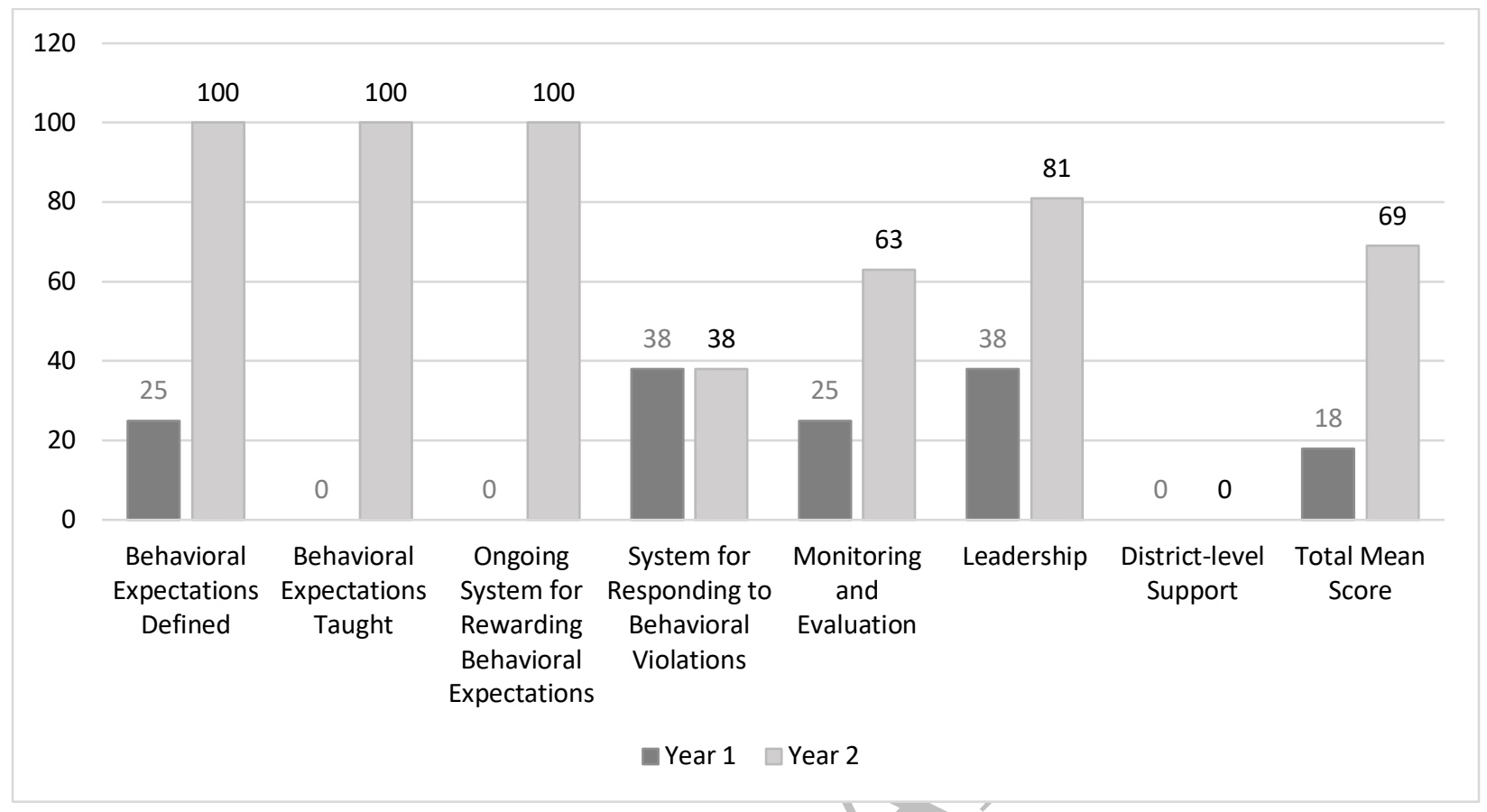

Figure 1. Percentage of critical components in place using the School-wide Evaluation Tool 